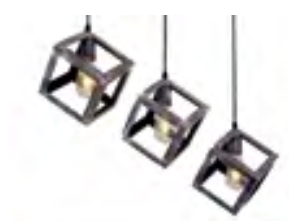

"I
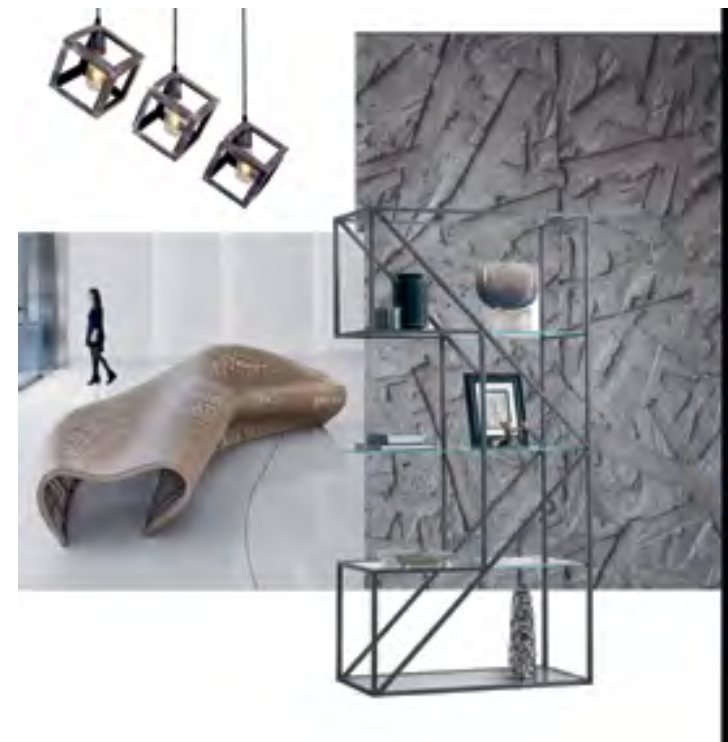
\title{
between the global and the local
}

Дизайн как пространство компромисса глобального и локального / Design as a space of compromise

текст

Ольга Железняк

Иркутский национальный исследовательский технический университет /

text

Olga Zheleznyak

Irkutsk National Research Technical University

\section{^ Поиски образов}

и дизайн-кодов для идентификации университетской среды.

Автор Д. Петухова, руководитель М. В. Корелина. Каф. Дизайна ИРнитУ

1. см. работы R. Robertson, M. Featherstone, S. Lash A. Hassi, G. Storti, B. Poyдометофа, Ю. Ф. Абрамова, А. Н. Лапшина, В. В. Мантатова, А.С. Маршаловой, А.С. Новоселова, Г.В. Чер кашина, Н.С. Коноплёва, В. А. Лазебного, В. В. Кардашевского и др.
«Мир миров», в котором мы живем, по М. Я. Гефтеру, представляет собой «совместность несовпадающих векторов развития, <...> взаимопритирку разных культур и цивилизаций» [10, с. 42]. Экспансия глобализационных процессов в разные сферы жизни и деятельности, породившая по всему миру ответную защитную реакцию в виде развития местных инициатив и традиций, делает актуальным исследование проблем взаимодействия этого «мира миров» как глобального и локального, изучение механизмов становления новых норм, влияния транснациональных компаний на жизнь местных/региональных культур.

Разные обозначения этого феномена и его интерпретации - креолизация, «делать что-либо по-туземному», глокализация, гибридизация и пр. - сегодня приобретают значимость и занимают все больше места в теоретических исследованиях и практических разработках как ответ на тотальную глобализацию и возникающее противостояние разрушению осознания пространственных дистанций, ослаблению взаимосвязей между территориями и культурными ресурсами, атрофии идентичности и утрате местных традиций и обычаев [3].

«Несущей конструкцией» этих процессов являются коммуникации, обеспечивающие непрерывную трансляцию интеллектуальных и материальных ресурсов и продуктов по всему миру и экспансию приоритетной культуры. Они нацелены на распространение ценностей, концептов и стандартов, а также культурных продуктов и изделий с использованием различных медиасредств, в т. ч. цифровых, систем образования и массовой культуры, современных технологий и форм рекламы и пр. [12, с. 6].

Экспансия ведущих культур порождает попытки трансформировать коды локальных культур извне, что негативно сказывается на процессах самоотождествления и достижения целостности информационной и ментальной идентичности в каждом конкретном регионе. Безоговорочное присвоение кодов и норм глобальных культур возможно в странах, разделяющих аналогичные ценности и способных использовать транскультурные стандарты как собственные. Так, в частности, процесс американизации прежде всего зависит от восприимчиво-
Противоречивая целостность глобального и локального рассматривается как источник транснационального и регионального развития. Важным аспектом глокализации, обеспечивающим «оформление» и внедрение базовых представлений в реальную жизнь, пространством компромисса и построения взаимодействия глобального и локального служит дизайн. Наглядно это демонстрируют современные системы брендинга. Дизайн как научно-образовательное пространство в глокальных дискурсах представляется на опыте работы кафедры дизайна ИРНИТу.

Ключевые слова: дизайн; глобальное; локальное; глокализация; стратегии брендирования; мировые бренды; кафедра дизайна ИРниту; дизайн-образование. /

The contradictory integrity of the global and the local is viewed as a source of transnational and regional development. Design is an important aspect of glocalization, which ensures the "formulation" and introduction of basic ideas into the real life, and a space of compromise and interaction between the global and the local. It is clearly demonstrated by contemporary branding systems. Design as a scientific and educational space is presented in glocal discourses through the work of the Design Department of INRTU.

Keywords: design; global; local; glocalization; branding strategies; world brands; INRTU Design Department; design education. сти местных культур к нормам и артефактам из американской культуры.

В мире глобальных коммуникаций, ориентированных на продвижение транснациональных ценностей, стандартов и кодов, в духе современных трендов и сетевых принципов начинают разрабатываться и внедряться концепции мягкого суверенитета, гуманитарной интервенции, движения этносов к самоопределению. Фактически происходит прорастание мира глобального через мир локальный, их соотнесенность и взаимопроникновение, что воплощается в концепции глокализации [12, с. 7].

Как актуальная целостность социально-экономического и культурного развития глокализация представляет собой сосуществование и взаимодействие разнонаправленных тенденций. Она предопределена тем, что в процессе глобализации вместо слияния и унификации, ожидаемого размывания региональной специфики происходит нарастание тенденций сепаратизма по всему миру, обострение интереса к региональным и национальным отличиям, истокам аутентичности. Более того, исследования глокализационных процессов ${ }^{1}$ показывают, что транснациональные и местные тенденции и процессы взаимодополняемы, проникают друг в друга, составляя дихотомию.

Вместе с тем ряд авторов предлагает аналогию глокализации с гибридизацией и/или креолизацией, рассматривая различные версии взаимоотношения этих понятий, отражающих процессы перемешивания, мутации и/или адаптации различных норм, явлений, кодов и пр., создания специфических «миксов», один из компонентов которых непременно должен быть частью локальной культуры. Лежащий в основе этого процесс перманентного смешения культур предопределяет плюралистичность мира и самобытность результатов в различных регионах.

При этом транскультурная конвергенция различных «миров», явлений и процессов, их ассимиляция позволяют территориям не отказываться от собственной идентичности, порождая структурную гибридизацию, появление новых смешанных форм сотрудничества или развитие транслокальных культур «меланжа» [8].

Особым механизмом становления транскультурных образцов и, одновременно, сохранения и трансляции 


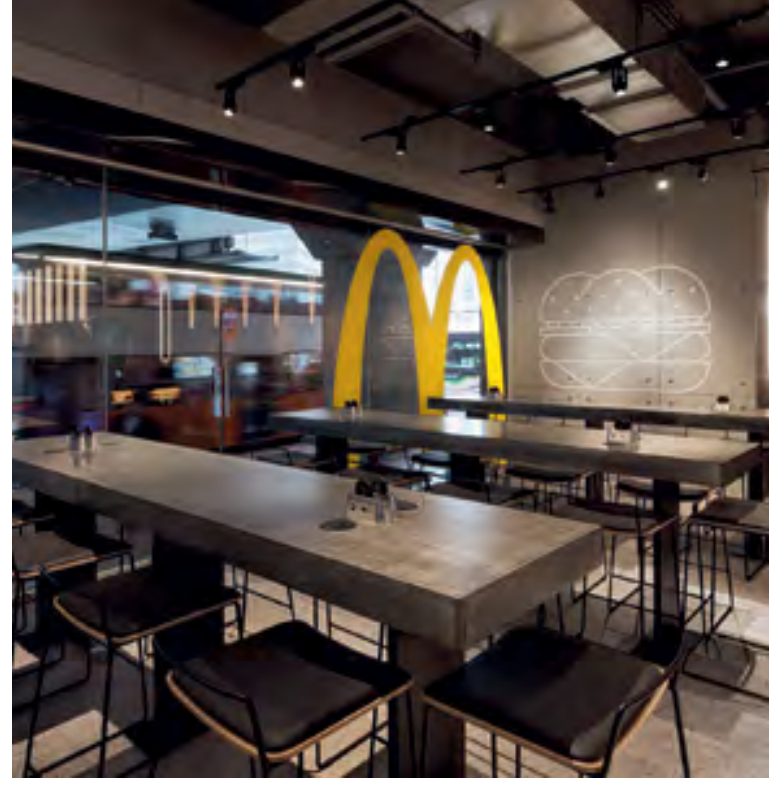

^ МакДоналдс в Москве: погружение глобального бренда в российскую реальность. - URL: https://roomble.mediasole.ru/makdonalds vypustil_lineyku_letney_odezhdy_i_tekstilya_s_burgerami

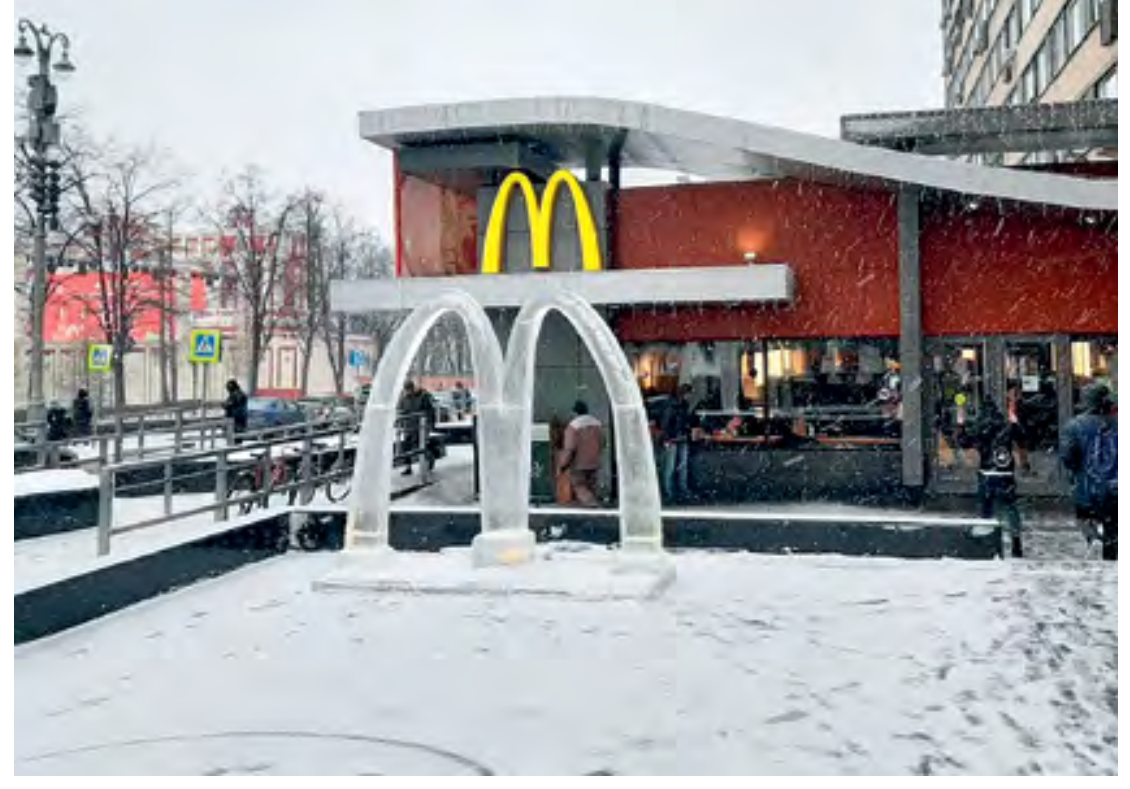

^ МакДоналдс в Москве: погружение глобального бренда в российскую реальность. URL: https://i.ytimg.com/vi/-sBZL4gWXHs/maxresdefault.jpg культурного ресурса места, его генетических кодов можно считать концепцию трансмутационного контакта. Это позволяет при введении в сложившийся региональный континуум нового-иного, осуществляемом через контакт/трансмутацию нового с наличным (существующим комплексом архетипов места и культурных образцов), находить подобия, прототипы нового в уже сформировавшейся системе, используя разные формы их взаимодействия и погружения, отождествления своего с чужим и, напротив, чужого со своим [11].

Модели глокализации, как правило, опираются на сетевые формы коммуникации, способствующие мировому развитию, становлению «мира миров», обеспечению процветания «местностей» [18]. Принимая во внимание тот факт, что ключевая идея глобализации заключается в увеличении мобильности различных потоков (материальных, финансовых, информационных, людских и пр.), наряду с формированием планетарного рынка производства и потребления универсальных товаров, важным становится наличие дифферинцированности между «мирами», территориями и культурами [14].

В усилении регионального разнообразия, в транслокальном слиянии и культурном смешении или гибридизации [3] также заинтересованы и транснациональные корпорации, являющиеся основными движителями и проводниками глобализационных процессов и обладателями глобальных брендов.

Складывающаяся при этом окружающая среда представляет собой глокализующееся пространство, которое образует «сектор реальной действительности, где главное положение отведено очеловеченным бытом, массово осваиваемым участкам земной поверхности. Глокализация, воспроизводя антропоморфно насыщенные участки земной поверхности, вбирает в себя глобальные очертания сущего и одновременно с этим локализует их конкретными <...> установками» $[12$, с. 10].

Выступая современной формой отражения существующей реальности, глокальность является неизменной частью планетарной жизнедеятельности человека. Специфическим средством оформления этой реальности, обустраивания ее и приведения в соответствие с «мер- ками человечности» и процессами глокализации может служить пространство дизайна.

\section{Дизайн как неизменная часть современного мира и процессов глокализации}

Тотальность дизайна в современном мире, его органическая погруженность в технологии и инновации, а также необходимость соответствия дизайна месту, его одновременное существование в рамках глобального и локального, универсального и уникального превращают дизайн в актуальное пространство для обсуждения современных проблем глокализации, трансмутации глобального в \с локальным и наоборот.

В процессе сорганизации глобального с локальным, необходимости удержания глобального «сложившимся бытообустройством» [12, с. 11], аутентичными нормами устройства жизни и предметно-пространственной среды все более важное значение приобретают местные традиции и обычаи, дизайн-коды среды и национальные культуры.

Происходящие при этом смешение и трансмутация норм затрагивают прежде всего поверхностные элементы культуры, в то время как глубоко укоренившиеся коды культуры зачастую в гибридизацию не вовлекаются [3].

Эти трансформации распространяются на жизнь, стили и развитие трансконтинентальных корпораций и влияют на изменение их имиджевых концептов, ассортимент и дизайн продвигаемой продукции, формы коммуникаций. Даже такие идеологи глобализации, как мировые бренды вынуждены находить новые стратегии развития, учитывающие локализацию, которая становятся частью современного представления о брендировании и основой для построения имиджа. В частности, уже с 2012 г. агентством Cohn\&Wolfe, входящим в крупнейшую коммуникационную группу мира, проводится рейтинг аутентичных брендов, в котором участвуют более 1600 мировых компаний. Основными критериями и атрибутами аутентичности бренда являются: «подлинность» (имеется в виду уникальность бренда и репутация), его «надежность» и «уважение к потребителю». Самым аутентичным брендом 2021 г. признан глобальный медиа-бренд Disney; в тройку лидеров также вошли BMW и Microsoft. 

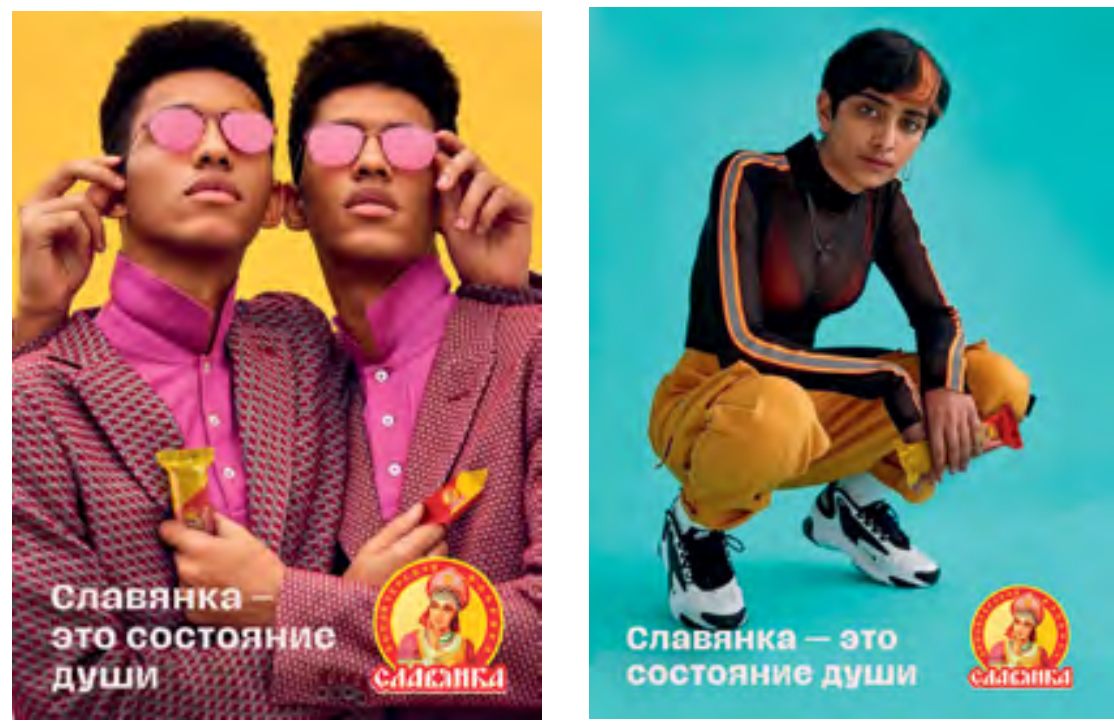

^ Новый глокальный key-visual бренда «Славянка». - URL: https://www.sostav.ru/publication/ kreativ-bez-algoritmov-formul-i-telepatii-ili-ne-zastavlyajte-klientov-dumat-49635.html
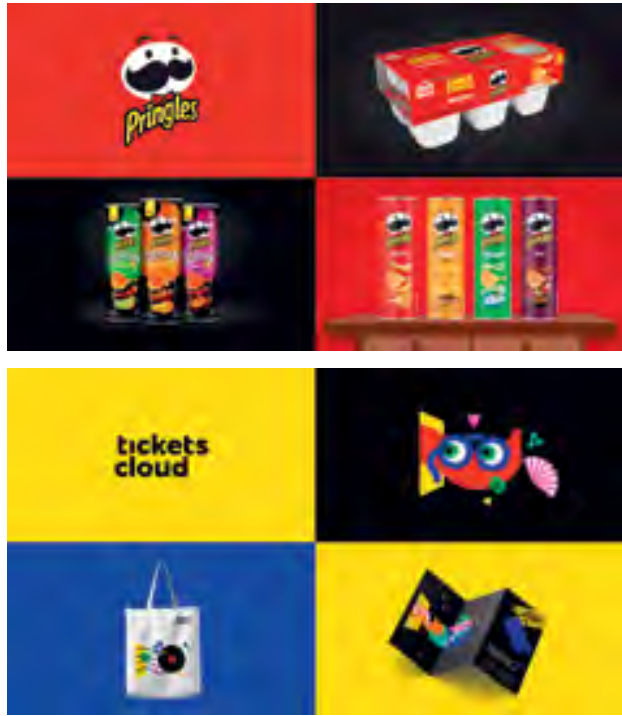

^ Предложения студии Pixies по ребрендингу популярных брендов на основе архетипов. - URL: https://www. sostav.ru/publication/dlya-chego-nuzhen-rebrending12-arkhetipov-brendinga-ili-kak-nai-ti-svoi-imidzh-iotstroitsya-ot-konkurentov-47437.html
Одним из трендов рейтинга этого года является внимание к местным имиджам и брендам, что оказывается особенно актуальным для стран с высоким ВВП, проявляющим наибольший интерес к «домашним» брендам (Швеция и Великобритания). В Китае и Гонконге одинаковое предпочтение отдается отечественным и мировым брендам; иностранные бренды получают явный приоритет в Индии и Индонезии [1].

В целом глокализация, трансформируя стратегию брендинга, порождает необходимость учета уникальной культуры потребителя. Локализации подвергается сам продвигаемый продукт со всеми компонентами, комплекс коммуникаций и собственно имидж компании. При этом глокализация активно внедряется компаниями, бренды которых традиционно входят в число ключевых проводников глобальных идей, стандартов и продуктов.

Так, московский McDonald»s предлагает особую гибкую систему организации среды, функционирования предприятий и продвижения рекламы. Здесь можно часами общаться за чашкой чая или кофе, что недопустимо в классических американских пунктах быстрого питания, поскольку подобный подход препятствует успешному бизнесу.

Кроме того, к концу года для России McDonald»s планирует полностью поменять дизайн упаковки, чтобы сделать продуктовую линейку сетевого пакета частью общей графической системы..Авторы новой упаковки (агентство Pearlfisher) полагают, что обновленная версия дизайна бренда создаст «ощущение радости и легкости, благодаря яркой графике» [6]. «Простота и смелость» предложенного дизайна как новый аутентичный образ символизируют готовность компании к изменениям в соответствии с региональной спецификой и современными трендами. Использование при создании новых элементов бренда близкой к природной цветовой палитры и отказ от применения пластиковых пакетов демонстрируют приверженность компании принципам экологичного природосообразного производства и сбалансированного питания [6].

Развитию этой концепции следует решение интерьера нового МакДональдса в Москве, key-visual которого «Естественность». Для раскрытия образа используются природный колорит, дерево и кожа, уникальные формы пространственной организации, набор аутентичной мебели с традиционными деревянными стульями и романтичными садовыми лавочками.

Адаптация идеалов быстрого питания в Китае, Юго-Восточной Азии и Индии сопровождается исследованием традиционных вкусов и современных вариаций смешения еды, созданием аутентичных интерьеров и kеуvisuals, что переводит эти предприятия из ранга закусочных быстрого питания в заведения, обслуживающие «верхний средний класс», и демонстрирует приоритет локального, местного «над макдональдизацией, американизацией и глобализацией» [3].

Складывающаяся практика адаптации и \или присвоения брендов, построения взаимодействия культурных кодов, создания новых форм коммуникаций и трансмутация норм выявляют «зеркальные» возможности для продвижения местных брендов на глобальный рынок.
«Восточная» интерпретация мировых брендов китайскими криэйторами. - URL: https://bigpicture. ru/abibas-i-ego-druzyapopulyarnye-brendy-vkitajskoj-interpretacii
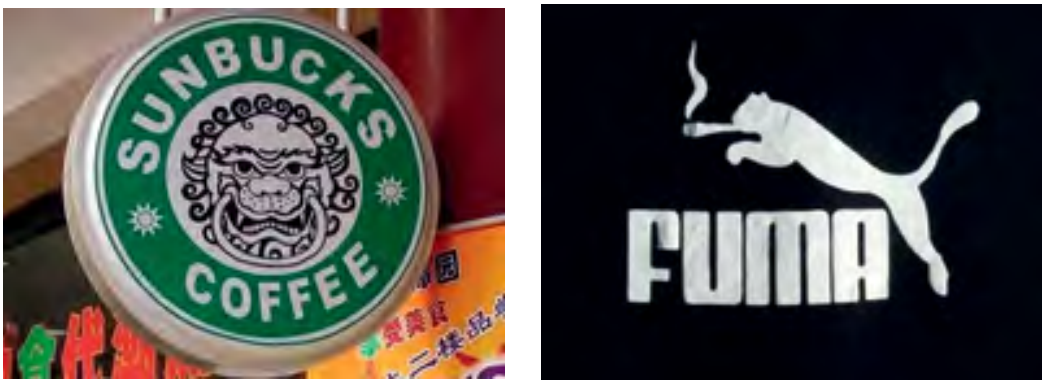

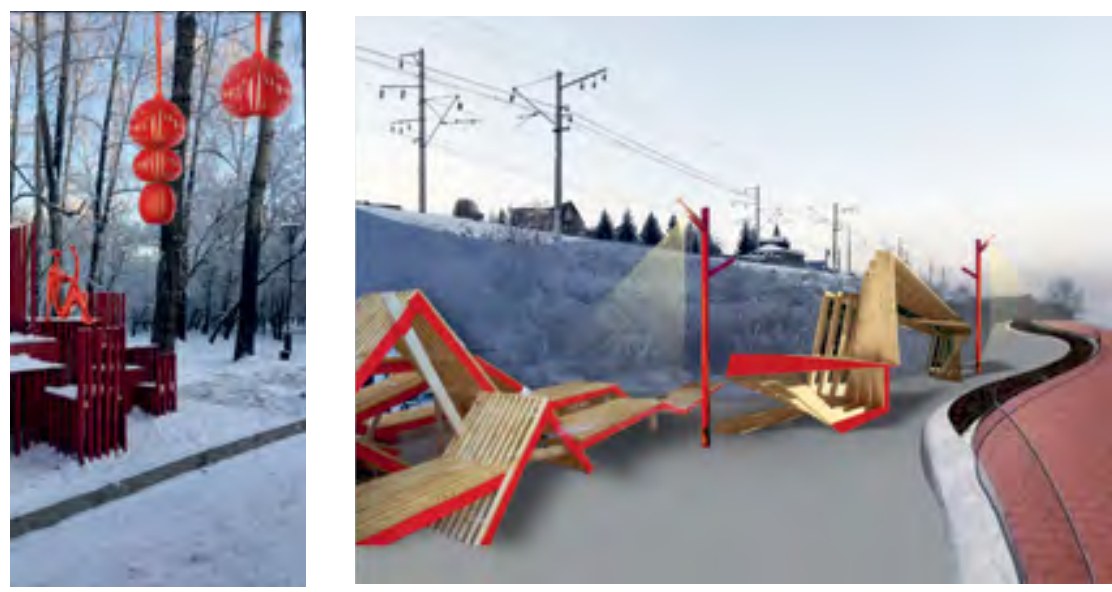

^ Концепты глокального дизайна для городских интерьеров Иркутска.

Авторы А. Хайрутдинова, С. Никитина, руководитель М. В. Корелина. Каф. Дизайна ИРНИтУ

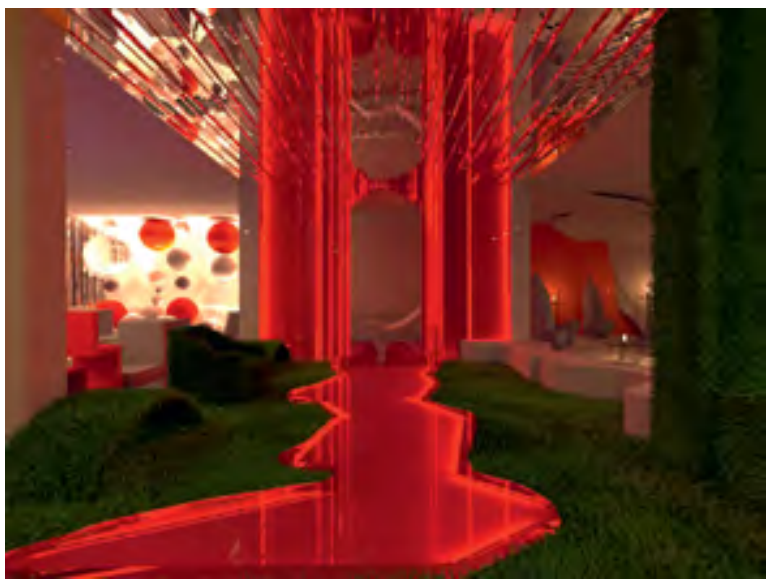

^ Арт-резиденция ИРНИтУ как имиджевое пространство. Фрагмент. Автор С. Горбунова, руководитель О. Е. Железняк. Каф. Дизайна ИРНИТУ ных товаров, общедоступных и пригодных для формирования аутентичной среды и обустройства дома в любом регионе мира, соответствуют концепции «демократичного дизайна», продвигаемой компанией ИКЕА и позволяющей «совмещать возможности поставщика с потребностями заказчика» [10].

Концепция демократичного, но качественного дизайна пронизывает все структурные составляющие компании ИКЕА - от центра разработки дизайна в Эльмхульте и производственных предприятий до деятельности мастерских местных ремесленников, расположенных в Индии, странах Юго-Восточной Азии и др. Продвигать продукцию компании на иностранные рынки, сохраняя основные идеалы бренда, помогает использование системы франчайзинга.

В целом популярность бренда в среднем сегменте во многом предопределена экологическими идеями, демократичностью и профессиональной продуманностью дизайна, возможностью комбинирования и авторского участия разных групп потребителей в создании уникальной среды, а также соотнесенностью с базовыми архетипами региональных культур. Согласование продукции и визуального ряда бренда с культурными архетипами привносит в процессы глокализации и развития бренда, его коммуникации с потребителем на разных мировых площадках дополнительный смысловой слой, позволяет более точно отражать суть глобальных и локальных ценностей бренда и его уникальность [2].

Одним из важных современных трендов глокализации оказывается значительный рост влияния высокотехнологичных компаний, поощряющих развитие виртуальной среды, цифровых технологий в целом. Лидерами среди них на сегодня являются Microsoft, Amazon и Apple. Активно развиваясь в интернет-пространстве, феномен глокализации формирует разнообразные технокультурные ландшафты (медиа-, техно-, этно-, финансовые и др. пейзажи), цифровые миры и формы коммуникации. Они служат для исследования компромиссов и разрывов между глобальным и местным/региональным, между экономикой, культурой и социумом, составляют различные пласты глобализации и трансформации культурных потоков [3]. Дигитализация современного мира вообще играет ключевую роль в дизайн-глокализации, начиная от дизайна виртуального мира и заканчивая дизайном интерьерной и городской среды, а также производством современных товаров и объектов предметно-пространственной среды, в Т. ч. через 3D-принтирование как новую технологию создания изделий, приближающую универсальную брендовую продукцию к заказчику.

Не менее актуальным трендом глокализации является эко-дизайн, который способствует построению взаимодействия, нахождению компромисса глобального и локального. Будучи одной из приоритетных концепций в современном дизайне, эко-дизайн определяется как направление, которое базируется на идее защиты глобальных и локальных/региональных аспектов природной и культурной среды, ориентируется на сохранение естественных систем и создание соответствующих взаимосвязей между компонентами. 0 н содействует становлению компромисса и гармонии между планетарным/космическим масштабом и самым малым локусом, эйдосом места.

Но и роль цифрового дизайна, и значение эко-дизайна («зеленого дизайна») в формировании дихотомии глобальное - локальное, в построении взаимоотношений транснационального и регионального как пространства глокализации требуют отдельного исследования и специального описания.

\section{Дизайн как научно-образовательное пространство и дискурсы глокализации. Опыт работы кафедры дизайна и СНПЦ формирования предметно- пространственной среды ИРнИту}

Выстраивая модель создания, получения и распространения знаний в ситуации глокализации, сложного взаимодействия глобального и локального, отдельные исследователи $[4 ; 13]$ предлагают использовать две группы знаний - знания, ограниченные местной средой, и свободно «путешествующие по миру» систематизированные знания. H. Bathelt, A. Malmberg, P. Maskell [4], выделяя сферу неявной трансляции знаний и группу знаний, обладающих местными особенностями (так называемого «молчаливого знания»), подчеркивают, что оно принадлежит конкретному региону и формирует- 
ся при взаимодействии местных структур бизнеса, ВУзов и исследовательских учреждений. Во избежание замкнутости региона должны происходить информационный обмен систематизированными знаниями и направленная, целевая коммуникация с внешними контрагентами [13]. Это обеспечивает взаимообмен и циркуляцию знаний, выход региональных знаний на глобальный рынок и погружение универсальных знаний в локальную культуру, что, вероятно, возможно при наличии равного пиетета к глобальному и региональному компонентам целостного пространства.

Ценность глокального знания, осознания сложного взаимодействия и компромиссов, сохранения паритета ценностей транснационального и регионального отмечают Джефри Брукс и Энтони Нормор [5]. При этом они предлагают лидерам образовательного процесса («современным образовательным лидерам») развивать и внедрять глокальную грамотность, систематизировав все знания по девяти основным направлениям развития глокализации.

В отечественной науке и образовании ситуация в настоящее время характеризуется явным перевесом в пользу ценностей глобального мира, ориентацией на мировые стандарты, на продвижение и признание внутренних достижений на глобальном рынке. В настоящее время приоритетным показателем качества работы становится представление ее за рубежом, публикация в изданиях, индексируемых в международных базах данных Scopus, Web of Science и др. Конечно, это не исключает исследования региональных проблем, обращения к местной специфике, но итогом все-таки должна стать зарубежная презентация результатов.

Начиная с Болонской декларации, в образовательной сфере происходят постоянные изменения, также связанные с встраиванием в мировой, глобальный рынок образовательных услуг и научных исследований. Это сопровождается серьезными структурными преобразованиями в ВУЗах и образовательной системе в целом, повышением роли научных исследований в деятельности ВУЗов, значительным увеличением внимания к наличию ключевых для статуса образовательных учреждений активных международных контактов и усилением интереса к изучению и использованию иностранных языков в ВУЗах.

Современная ситуация в дизайн-образовании и науке одновременно сложнее и проще, но с такими же приоритетами, т. к., с одной стороны, возможность представлять свои проектные работы (в т. ч. образовательные) на мировом рынке стала шире - от участия в международных выставках до дистанционной работы с зарубежными коллегами и заказчиками. С другой стороны, публикации исследований в зарубежных изданиях и изданиях, индексируемых Scopus и WoS, практически невозможны ввиду того, что количество отечественных издательств такого статуса крайне незначительно, а зарубежные публикации стоят чрезвычайно дорого.

Учитывая, что дизайн - это изначально пространство взаимодействия универсального/глобального и уникального/локального, проектные и исследовательские поиски в этой сфере остаются актуальными независимо от складывающихся реалий.

В связи с этим на кафедре дизайна/монументально-декоративной живописи и дизайна им. В.Г. Смагина ИРНИТУ ведутся исследования и проектные разработки по указанной тематике в рамках госбюджетной темы «Пространства культурной идентификации» (руководитель 0.Е. Железняк) и в программах деятельности Студенческого научно-проектного центра формирования предметно-пространственной среды (руководители О.Е. Железняк, М. В. Корелина).
ПЛАКАТЫ
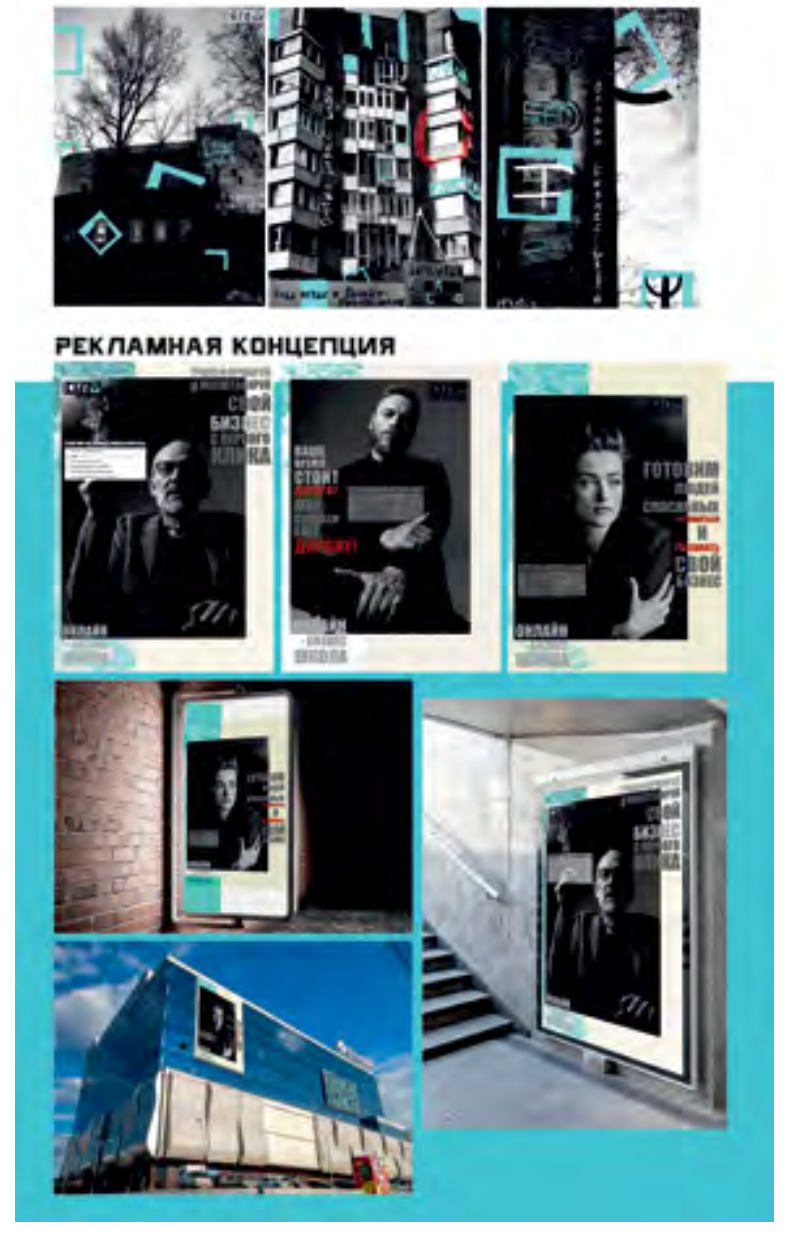

< Концепция бренда Онлайн-школы САФ.

Фрагмент.

Автор А. Юрьева, руководитель 0.Е. Железняк. Каф. Дизайна ИРнИтУ
Наиболее актуальные дискурсы исследований и художественно-проектной деятельности ближайшего времени посвящены следующим разработкам:

- Современная образовательная среда как пространство трансмутации глобального и локального, построения идентичности в рамках компромисса транснационального и аутентичного (на эту тематику в основном ориентированы работы Студенческого центра в последние годы);

- Образы и знаки города в мировой и отечественной практике - знаковая архитектура и градостроительные концепции, арт-дизайн и знаки места, дизайн-коды среды, информационная среда и графический дизайн в городском контексте, виртуальные миры и системы компьютерного моделирования, городские имиджи и колористика города, знаковые системы в среде современного города, городская реальность и художественные образы города в различных видах искусства, зимний город как имиджевый ресурс территории и др. (цикл художественно-проектных работ и научных исследований представлен на организованной ИРО СД России и ИРНИТУ Международной виртуальной выставке-конкурсе «0бразы и знаки города»);

- Городской интерьер и цветовые образы Иркутска как пространства идентичности места, отражения эйдоса, построенные на использовании реальных исследований специфики территории и на основе местных мифов;

- Специфика дизайна и художественно-проектной культуры в целом в эпоху новых информационных технологий;

- Коворкинги как гибридное пространство нового типа, обладающее в равной степени универсальностью и уникальностью, средство джентрификации, и/или «третье место». 
Теоретические исследования и художественно-проектные разработки темы идентичности как системы, порождающей и определяющей имиджи города и качество среды, ведутся по нескольким базовым направлениям: специфические особенности города как пространства культурной идентификации, обеспечивающие устойчивость территории и формирующие позитивный имидж места; художественно-проектная культура Сибирского региона и отдельных городов как пространство формирования жизнепригодной, художественно-привлекательной среды, повышения качества жизни и создания имиджей урбанизированных и малонаселенных территорий; город как бренд и корпоративный имидж предприятий условие формирования выразительного облика города и средство коммуникации, продвижения на глобальный рынок и др.

Исследования аутентичной культуры территории в контексте мировой практики, проводимые в рамках госбюджетной темы, положены в основу комплексных научно-проектных разработок для города Иркутска и Байкальского региона для формирования современного развивающегося города, в котором места освоены и означены.

Таким образом, противоречивая целостность глобального и локального является сегодня актуальным источником и потенциалом как транснационального, так и регионального развития и средством продвижения товаров, услуг и культур.

Важным дискурсом глокализационных процессов, обеспечивающим «оформление» и внедрение базовых представлений в реальную жизнь, пространством построения взаимодействия глобального и локального служит дизайн. Наиболее наглядно это демонстрируют современные системы брендинга, в которых проявляется роль и потенциал дизайна в становлении компромисса глобального и локального, а также показывается обратный процесс специфической интеграции дизайна и глокальности, изменение стратегий брендирования под влиянием глокализации.

Актуальные возможности использования дизайна в глокальных дискурсах представляет опыт научно-образовательных и проектных разработок кафедры дизайна ИРНИТУ и СНПЦ формирования предметно-пространственной среды, которые ориентированы на сохранение и культивирование уникального имиджа Иркутска и идентичности территории, продвижение бренда Иркутска на мировой рынок и встраивание его в транснациональный мир.

\section{Литература}

1. 100 самых аутентичных брендов. - IRL: https://www.sostav.ru/ publication/samye-autentichnye-brendy-21839.html

2. 12 архетипов брендинга, или как найти свой имидж и отстроиться от конкурентов. - URL: https://www.sostav.ru/publication/dlyachego-nuzhen-rebrending-12-arkhetipov-brendinga-ili-kak-nai-ti-svoiimidzh-i-otstroitsya-ot-konkurentov-47437.html

3. Abderrahman Hassi, Giovanna Storti. Globalization and Culture: The Three H Scenarios. //https://www.intechopen.com/chapters/38348

4. Bathelt H., Malmberg A., Maskell P. Clusters and Knowledge: Local Buzz, Global Pipelines and the Process of Knowledge Creation// Progress in Human Geography. February, Vol. 28. No. 1. 2004

5. Jeffrey S. Brooks, Anthony H. Normore. Educational Leadership and Globalization: Literacy for a Glocal Perspective (англ.) // Educational Policy. - 2010-01-01. - Vol. 24, iss. 1. - P. 52-82.

6. McDonald's полностью изменит дизайн упаковки в России к концу года. - URL: https://www.forbes.ru/newsroom/biznes/422521mcdonalds-polnostyu-izmenit-dizayn-upakovki-v-rossii-k-koncu-goda
7. Mike Featherstone, Scott Lash, Roland Robertson. Global Modernities. - SAGE, 1995-01-01.- 306 c.

8. Pieterse J. N. Globalisation as hybridisation // International Sociology, June 1994. - URL: https://journals.sagepub.com/ doi/10.1177/026858094009002003

9. Актуальные вопросы глобализации: «круглый стол» МЭ и МО // Мировая экономика и международные отношения. - 1999. - № 5. C. 41-57

10. Все об ИКЕА. - URL: https://www.ikea.com/ru/ru/this-is-ikea/ about-us/missiya-i-biznes-ideya-pub25f05283

11. Железняк, 0. 0 трансмутации «нового в/с наличным» // Проект Байкал. - 2021. - № 67. - С. 24-29

12. Коноплёв, Н. С., Лазебный, В. А., Кардашевский, В. В. Феномен духовной глокализации социума как способ действенного преодоления односторонностей глобалистики : монография. - Иркутск : Изд-во «0ттиск», 2016. - 120 с.

13. Лысенкова, М. А. 0 возрастающей роли глокализации в развитие региональных инновационных систем. - URL: http://www.mce.su/ eng/archive/abstracts/mce25/sect286/doc311038/

14. Транслаборатория. Наша федерация будет глобальной // ИNAЧЕ. - 2003. - № 5. - URL: http://www.inache.net/print/signs/754

\section{References}

12 Arkhetipov brendinga, ili kak naiti svoi imidzh i otstroitsya ot konkurentov [12 archetypes of branding, or how to find one's own image and tune out from competitors] (2021, February 23). Retrieved from https://www.sostav.ru/publication/dlya-chego-nuzhen-rebrending12-arkhetipov-brendinga-ili-kak-nai-ti-svoi-imidzh-i-otstroitsya-otkonkurentov-47437.html

Aktualnye voprosy globalizatsii: “kruglyi stol" ME i MO [Topical questions of globalization: "round table" of WE and IR] (1999). World economy and international relations, 5, 41-57.

Bathelt, H., Malmberg, A., \& Maskell, P. (2004, February). Clusters and Knowledge: Local Buzz, Global Pipelines and the Process of Knowledge Creation. Progress in Human Geography, 28(1).

Brooks, J. S., \& Normore, A. H. (2010, January 1). Educational Leadership and Globalization: Literacy for a Dulneva, M. (2021, March 3). McDonald's polnostyu izmenit dizain upakovki v Rossii k kontsu goda [McDonald's will fully change the packaging design in Russia by the end of the year]. Retrieved from https://www.forbes.ru/newsroom/ biznes/422521-mcdonalds-polnostyu-izmenit-dizayn-upakovki-v-rossiik-koncu-goda

Featherstone, M., Lash, S., \& Robertson, R. (1995, January 1). Global Modernities. SAGE.

Glocal Perspective. Educational Policy, 24,(1), 52-82.

Hassi, A., \& Storti, G. (2012, August 22). Globalization and Culture: The Three H Scenarios. Retrieved from https://www.intechopen.com/ chapters/38348

Ippolitova, N. (2016, April 22). 100 samykh autentichnykh brendov [100 most authentic bands] (2016, April 22). Retrieved from самых аутентичных брендов. - IRL: https://www.sostav.ru/publication/ samye-autentichnye-brendy-21839.html

Konoplev, N. S., Lazebnyi, V. A., \& Kardashevsky, V. V. (2016). Fenomen dukhovnoi glokalizatsii sotsiuma kak sposob deistvennogo preodoleniya odnostoronnostei globalistiki: monografiya [Phenomenon of spiritual glocalization of the society as a means of efficient overcoming onesidedness of Globalistics: monography]. Irkutsk: Izd-vo "Ottisk".

Lysenkova, M. A. (n.d.). 0 vozrastayushchei roli glokalizatsii v razvitie regionalnykh innovatsionnykh system [0n the growing role of glocalization in the development of regional innovative systems]. Mathematics. Computing. Education. Retrieved from http://www.mce. su/eng/archive/abstracts/mce25/sect286/doc311038/

Pieterse, J. N. (1994, June). Globalisation as hybridization. International Sociology. Retrieved from https://journals.sagepub.com/ doi/10.1177/026858094009002003

Translaboratoriya (2003). Nasha federatsiya budet globalnoi [0ur federation will be global]. INACHE, 5. Retrieved from http://www. inache.net/print/signs/754

Vse ob IKEA [Everything about IKEA] (n.d.). IKEA. Retrieved from https://www.ikea.com/ru/ru/this-is-ikea/about-us/missiya-i-biznesideya-pub25f05283

Zheleznyak, 0. (2021). On transmutation of "the new in/with the existing". Project Baikal, 18(67), 36-41. https://doi.org/10.51461/ projectbaikal.67.1751 